\title{
Les fleurs et les oiseaux du Jardin du Paradis de Francfort (1410-1420)
}

\section{Nicole Chambon}

\section{(2) OpenEdition}

\section{Journals}

Édition électronique

URL : http://journals.openedition.org/ifha/468

DOI : $10.4000 /$ ifha.468

ISSN : 2198-8943

\section{Éditeur}

IFRA - Institut franco-allemand (sciences historiques et sociales)

\section{Édition imprimée}

Date de publication : 30 septembre 2012

Pagination : 218-220

ISSN : 2190-0078

\section{Référence électronique}

Nicole Chambon, «Les fleurs et les oiseaux du Jardin du Paradis de Francfort (1410-1420) », Revue de I'IFHA [En ligne], 4 | 2012, mis en ligne le 14 février 2013, consulté le 03 mai 2019. URL : http:// journals.openedition.org/ifha/468 ; DOI : 10.4000/ifha.468

Ce document a été généré automatiquement le 3 mai 2019.

(CIFHA 


\title{
Les fleurs et les oiseaux du Jardin du Paradis de Francfort (1410-1420)
}

\author{
Nicole Chambon
}

La thèse se propose de lever certaines des incertitudes et ambiguïtés qui entourent le Paradiesgärtlein. Elles sont nombreuses, et concernent d'abord non seulement l'interprétation des divers éléments de la peinture, mais aussi les trois personnes grâce auxquelles un tableau voyait le jour à l'époque, c'est-à-dire le créateur, le commanditaire et le destinataire. A cet effet, une analyse minutieuse de l'œuvre et de ses moindres détails, mais aussi des nombreuses hypothèses émises par les critiques d'art était nécessaire. C'est pourquoi le travail s'articule selon un plan se découpant en trois phases: la présentation globale du tableau, puis une partie consacrée aux fleurs et enfin une dernière partie pour les oiseaux.

La première partie suggère toute la richesse du tableau. Elle montre que le peintre n'a rien laissé au hasard et que chaque détail est porteur de sens. La complexité de la problématique nous est révélée progressivement, en partant d'une description détaillée, pour ensuite évoquer en un long chapitre de plus de cent pages les controverses des critiques d'art à son sujet. Des connaissances bibliques sont nécessaires pour interpréter les personnages du tableau. En effet, mis à part Marie et son fils, l'identification des autres figures n'est pas évidente. La femme qui puise l'eau, celle qui tient le psaltérion et celle qui cueille des fruits peuvent incarner divers personnages bibliques. Concernant les hommes, on se heurte aux mêmes incertitudes, même si le dragon à leurs pieds semble indiquer qu'ils ont combattu et anéanti le mal.

La nature et la végétation présentes autour des personnages font tout autant l'objet de spéculation. L'arbre à tronc double rappelle le serpent biblique, mais aussi l'arbre de la vie. Les fleurs sont au nombre de vingt. Quant aux animaux, ils sont présents, non seulement au travers des treize oiseaux, mais aussi avec le singe, les poissons du bassin, le papillon, la libellule... Face à un tableau aussi foisonnant d'éléments de diverse nature, les interprétations foisonnent également. 
L'ambivalence du tableau est soulignée. Ce cadre bucolique abrite en effet des prédateurs comme le martin-pêcheur qui saisit un poisson, le rouge-gorge qui attrape un insecte dans l'œillet. D'autre part, elle met en évidence l'influence courtoise, sensible dans la finesse et la grâce des figures, la symétrie de la composition. Les femmes se livrent à des activités domestiques : cueillir des fruits, puiser de l'eau, éduquer l'enfant à la musique. Seule Marie a une occupation plus intellectuelle, la lecture de la Bible. Ce tableau illustre un rêve de paix et d'harmonie qui s'explique par la vie troublée des gens d'une époque marquée par des tremblements de terre, des épidémies de peste, des guerres. La mort omniprésente suscite une fascination pour le paradis, lieu d'où la mort est évacuée. Cependant, ce jardin enclos, dont sont représentés deux murs d'angle, matérialise également, en tant que hortus conclusus, la virginité de Marie. Il revêt donc des significations variées.

Si le choix a été fait de parler des fleurs et des oiseaux, c'est d'abord parce que la nature est entrée dans la peinture occidentale au XVe siècle, et ensuite parce que les Jardins du paradis confèrent une portée allégorique à cette représentation minutieuse d'un cadre naturel. Les fleurs dessinées sont celles qui fleurissaient dans les jardins médiévaux: roses, lys, pâquerettes, marguerites, violettes etc., et elles sont porteuses d'un symbolisme qu'il est intéressant de décrypter. Ainsi n'est-il pas indifférent que l'on puisse décompter seize roses, neuf lys, douze iris. Ce tableau est avant tout raffiné, novateur et extrêmement construit.

Ce travail de thèse nous plonge dans un univers enchanté et, en même temps, extrêmement codifié. Il évoque non seulement la signification religieuse des fleurs, mais aussi leurs caractéristiques médicinales, et les qualités que leur attribue la tradition populaire. Il remonte jusqu'à l'Antiquité pour signaler, par exemple, que la fête des roses, les Rosalies, faisait partie alors des cérémonies liées au culte des morts. Il indique également l'étymologie des noms: la primevère sauvage a pour nom primula veris, autrement dit, première du printemps, symbole de fécondité, les œillets, dont le nom allemand est «Nägel», renvoient aux clous et donc à la souffrance et au calvaire christiques...

$\mathrm{Si}$, au terme de son travail, la doctorante ne parvient pas à identifier le peintre du Paradiesgärtlein, elle avance l'hypothèse qu'il s'agit d'un élève de John Siferwas. Concernant le commanditaire et le destinataire, elle défend l'idée que le tableau a été commandé par Catherine de Bourgogne, épouse de Leopold d'Autriche, pour la prieure du premier couvent réformé de Schoenensteinbach, Claranna von Hohenburg, comme pourrait le donner à penser la présence du bassin, illustration allégorique du nom Schoenensteinbach (schön Stein Bach). Cette supposition, étayée de façon convaincante, indique une piste aux critiques d'art et alimentera, sans nul doute, les débats à venir. 


\section{AUTEUR}

\section{NICOLE CHAMBON}

Nicole Chambon a présenté et soutenu sa thèse de doctorat le 17 octobre 2011 à l'université de Limoges sous la co-direction d'Aline Le Berre et de François Boespflug (université de Strasbourg). Elle a obtenu le prix Jean-Claude Cassaing de l'université de Limoges pour son travail. 